\title{
Disordered eating symptoms in Austrian men of different ages in the context of fitness centers
}

\author{
Barbara Mangweth-Matzek ${ }^{1}$ (D) $\cdot$ Benjamin Decker $^{1} \cdot$ Irene Erschbaumer $^{1} \cdot$ Verena Wurnig $^{1} \cdot$ Georg Kemmler $^{1}$. \\ Carina S. Bichler ${ }^{2}$. Claudia I. Rupp ${ }^{3}$
}

Received: 7 July 2021 / Accepted: 8 October 2021 / Published online: 2 November 2021

(c) The Author(s) 2021

\begin{abstract}
Purpose To assess eating behavior and associated factors in male fitness-center attendees.

Methods An anonymous questionnaire was administered to male fitness center members of Innsbruck (Austria), aged 18-80 years to assess socio-demographic features, weight history, sports activity, eating behavior including disordered eating based on the Eating Disorder Examination Questionnaire (EDE-Q) and DSM-5 key symptoms for eating disorders (anorexia nervosa, binge eating, bulimia nervosa, purging disorder) and body image. Three age groups (younger-middle-aged—older men) were compared regarding the variables described above.

Results A total of 307 men included displayed high rates of disordered eating as described by EDE-Q cutoff scores (5-11\%) as well as by DSM-5 eating disorder symptoms (10\%). While EDE-Q cutoff scores did not differentiate between the groups, the prevalences of DSM-5 eating disorder symptoms yielded significant differences indicating a clear decrease with increasing age. Binge eating and bulimic symptoms with excessive exercising as the purging method were the most often reported symptoms.

Conclusion Although described as typically female, disordered eating does occur in male fitness-gym attendees across all ages. The older the men, the less prevalent are the symptoms. Awareness of disordered eating and possible negative effects need to be addressed for attendees and trainers of the gym.

Level of evidence $\mathrm{V}$ - descriptive survey study.
\end{abstract}

Keywords Fitness center $\cdot$ Men $\cdot$ Eating disorder $\cdot$ Body image $\cdot$ Excessive exercise

\section{Introduction}

Preoccupation with beauty, fitness, and physical appearance in Western countries has led to increasing sports activities including exercising in the gym. For over half a century, slim body size is still the main ideal for the majority of women,

Barbara Mangweth-Matzek

barbara.mangweth@i-med.ac.at

1 Department of Psychotherapy, Psychotherapy and Psychosomatics, University Hospital of Psychiatry II, Medical University Innsbruck, Innsbruck, Austria

2 Department of Sport Science, University of Innsbruck, Innsbruck, Austria

3 Department of Psychotherapy, Psychotherapy and Psychosomatics, University Hospital of Psychiatry I, Medical University Innsbruck, Innsbruck, Austria it appears that a muscular body has become the ideal for a huge proportion of men next to fitness and leanness [1].

Although sports and exercise are the means to get or stay healthy, there is evidence of unhealthy consequences due to "overdosing sports" and lacking recovery [2]. Although not part of existing diagnostic classifications, "exercise addiction" describes a behavior that is researched quite intensively in the last years [3, 4].

Less known is that DSM-5 criteria of bulimia nervosa include "excessive sports activity" as a possible purging method in the context of bulimia nervosa describing compensation for binge eating and a method to prevent weight gain $[5,6]$. However, there is little data on this particular aspect, since most affected bulimic persons use self-induced vomiting or laxatives as a means to compensate against weight gain after binge eating [5].

There is scientific evidence that disordered eating is more prevalent among athletes than in the general 
population [7] based on the concept of "female athlete triad syndrome" first described in 1992 by the American College of Sports Medicine [8]. Although women are yet the predominant gender in eating disorders, men are also affected, but still "underdiagnosed, undertreated, and misunderstood" [9]. Next to those men who feel too fat and start to be anorexic or bulimic, there are men, who are described to become eating disordered driven by an ideal of Adonis-like muscularity [10-12]. The fitness centers as institutions of "health promotion" seem to be associated with an acceptance regarding "disordered eating behavior". This suggests that within the sports world, deviations of normal eating behavior are less likely stigmatized [10].

From this point of view, it has to be considered that athletic workout in the gym can be instrumentalized in the context of disordered eating behavior. It is of interest that to the best of our knowledge, there are only a few studies on fitness-center attendees and disordered eating and none regarding men of different ages in that context. Müller et al. [13] studied various forms of "addictive behaviors" among 128 fitness center clients aged on average 27 years (72\% male) and reported $11 \%$ showing eating disorder pathology based on the EDE-Q (8\% among the men). Stapleton et al. [1] compared male gym users $(N=140$, aged 18-65 years) and non-gym users $(N=40$, aged 18-63 years) regarding body image avoidance, body dissatisfaction and eating pathology and found significant differences between the two groups. Gym users endorsed higher body dissatisfaction and were engaged more in disordered eating than non-gym users. Lichtenstein et al. [14] reported that "compulsive exercise" might be a socially accepted behavior in fitness centers, and described a linkage to eating disorder pathology, emotional problems and personality traits such as perfectionism, neuroticism or narcissism. There are a few studies that focus on fitness instructors' and employee's recognition or suspicion of disordered eating and excessive exercise in participants [15-17]. This research suggests that there is a high level of insecurity in identifying and managing the problems, to differentiate between healthy and unhealthy behavior and many open questions how to address the issues interpersonally.

In the context of Austrian data and eating disorders in males, we have published a community study in 2016 [18] identifying $32(7 \%)$ participants, aged $40-75$ years, meeting criteria for eating disorder symptoms as defined by DSM-IV as compared to 438 (93\%) men with normal eating.

In summary, research in males with disordered eating is still very marginal, although new characteristics have been described $[9,11]$.

The aim of this study was to examine eating behavior (including disordered eating assessed by the EDE-Q and by DSM-5 key symptoms of eating disorders), sports activity, and body image in male fitness-center attendees of different age groups (younger — middle-aged—older men).

\section{Method}

\section{Study design and participants}

We distributed our anonymous questionnaires to 652 male participants of the two largest fitness centers in Innsbruck, Austria, aged 18-80 years. Interested men were administered the questionnaire including the informed consent and were asked to return both completed forms into a sealed box positioned in the corner of the fitness center's entrance. We recruited men of all ages and combined two decades of age to form three groups including younger (18-40 years), middle-aged (41-60 years) and older men (61-80). 307 subjects returned and completed the questionnaire and were included in our statistical analysis (yielding a participation rate of $45.7 \%$ ). Since two men did not report their age, we did the statistical analysis regarding the three age groups based on 305 men. We do not have explicit information about those men who did not return the questionnaire.

All study procedures were approved by the Ethics Commission of the Medical University of Innsbruck, Austria.

\section{Study instrument}

To maximize the participation rate, we kept the questionnaire as brief as possible.

Demographic characteristics included age, country of origin, marital status, number of children, and level of education.

Weight history was obtained from self-reported height and weight (current, highest, lowest since adulthood, and desired). From these data, body mass indices (BMI) were calculated.

Aspects of sports activity were assessed by two questions: 1) "What is the frequency of your sports activity?" (5-point Likert response option ranging from daily to never) (neverfor those who only use the spa area), and 2) "Why do you regularly do sports?" offering four options to check with yes or no (e.g., to lose weight, to gain muscularity, to relax, to do competitions).

There are no existing, standardized questions to prove the criteria of "excessive sports" [19] described in DSM-5 as a specific purging method of bulimia nervosa defined by a) "colliding with other important activities or" b) "performed at inappropriate times and places or" c) "continued despite injuries or medical complications" [5, page 546]. Therefore, we used selected items from the Exercise Dependence Scale (EDS-21) $[20,21]$ and the Exercise Addiction Inventory (EAI) $[22,23]$ since the whole instruments assessed 
subscales that were not of interest for our analysis. The instruments aim to assess maladaptive patterns of exercising based on 21 and 6, respectively, items to describe subscales such as "tolerance", "withdrawal", "intention effect", "lack of control" "time", "reduction in other activities", "continuance" with six-point Likert response options including $1=$ never till $6=$ always. The selection of the single items was based on the best matches with the three DSM-5 criteria described above: "I have conflicts with my family or friends because of the amount of my exercise" (=item 2 of the EAI for criteria a); "I think about exercise when I should be concentrating on school or work " (=item 12 of the EDS) for criteria b); "I exercise despite recurring or persistent physical problems or injuries" (summary of items 2, 9, 16 of EDS for criteria c). At least one of these selected items had to be scored equal or higher than 4 (=often/ very often/ always) in order to meet criteria for "excessive exercising" as described above.

Eating behavior was assessed by the self-report Eating Disorder Examination Questionnaire (EDE-Q) [24, 25]. This psychometrically validated instrument describes eating behavior and body image occurring during the past 28 days based on four subscale scores [describing (1) restraint eating, (2) eating concern, (3) shape concern, (4) weight concern] and a global score for these behaviors. We used the menspecific cutoff-score $>1.68$ [26] and the common cutoffscore $\geq 2.3$ [27] to indicate disturbed or disordered eating.

In addition, in line with prior research [28], we assessed key symptoms of clinical eating disorders as defined by DSM 5 such as (a) BMI $<18.5$ plus weight phobia (of anorexia nervosa, AN), (b) binge eating at least once per week for more than 3 months (of binge eating disorder, BED), (c) binge eating and purging (of bulimia nervosa, $\mathrm{BN}$ ) and (d) purging without binge eating (of purging disorder, PD). Specifically, we classified men as having eating disorder symptoms (EDS) if they reported any of the four current characteristics (a, b, c or d). Purging was defined to include vomiting, laxative abuse, diuretic abuse, strict dieting or excessive exercise as methods of weight control. As defined above, we proved criteria of "excessive exercising" as a bulimic purging method according to DSM-5 criteria. Finally, we asked respondents, deliberately low threshold (without criteria of treatment or diagnosis), whether they ever had an eating disorder to also examine subjective awareness of disordered eating. Further, our questionnaire included frequency of lifetime diet behavior to prevent weight gain or to lose weight offering three answering options (never, up till 20 times, and $>20$ times).

Body image focusing on satisfaction with weight, shape and body was assessed by the three questions: "How satisfied are you with your current weight?", "How satisfied are you with your current shape?" offering three answers (satisfied, moderate satisfied, dissatisfied) and "Do you like your body?" offering answering options: "yes", "no", "I do not know."

\section{Data analytic plan}

Statistical analysis was performed using SPSS (version 26) [29]. To compare the three age groups based on 305 men (18-40, 41-60 and 61-80 years) with respect to demographic, weight and sport characteristics, we used the Kruskal-Wallis test for ordinal and for continuous variables (as the majority of them was not normally distributed), and the Chi-square test for categorical variables. Post hoc pairwise group comparisons were performed using the Mann-Whitney $U$ test and the Fisher's exact test. As the three groups differed significantly with regard to current BMI, the potential confounding effect of this variable was taken into account in all subsequent analyses. We used analyses of covariance for group comparisons involving continuous variables, logistic regression for binary-dependent variables, and ordinal regression for ordinal-dependent variables, always with adjustment for current BMI. Post hoc pairwise group comparisons were performed only if the overall comparison of the three groups yielded statistical significance $(p<0.05)$. This sequential testing procedure grants in the case of the three groups that the family-wise alpha level of 0.05 is retained without correction for multiple testing [30]. An alpha level of 0.05 was used to determine the statistical significance of all results.

\section{Power analysis (post hoc sensitivity analysis)}

The following power analysis was conducted using the program GPower, version 3.1.7. It is based on standard assumptions regarding type 1 error $($ alpha $=0.05)$ and power (1-beta $=0.8)$. Then the sample of $305 \mathrm{men}$, split into three age groups of unequal size (age 18-40: $n=169$, age 41-60: $n=81$, age 61-80: $n=55$, see "Results"), is sufficiently large to detect in an analysis of covariance with three groups and up to three covariates, an effect size $f=0.231$. This is a medium effect size according to Cohen's classification [31]. In a logistic regression analysis, e.g., for comparing the three age groups regarding the prevalence of EDS, the above sample size allows detection of ORs of 3.00 for comparison of the two younger age groups and ORs of 3.55 and 3.90 for the other two comparisons (youngest vs oldest group, the two oldest groups), provided that the prevalences to be compared are greater than 0.1 . For smaller prevalences, the values of the detectable ORs increase; for rates between 0.05 and 0.1 , they are 4.16, 5.14 and 5.74, respectively. These are medium $(\mathrm{OR} \approx 2.7-4.7)$ to large $(\mathrm{OR}>4.7)$ effect sizes [32]. 


\section{Results}

\section{Demographic, weight and sport characteristics}

Table 1 shows a comparison of demographic, weight and sport characteristics by age group. The majority of the demographic and weight-related variables differed significantly between age groups, reflecting their variability over the lifespan. The older the men, the more often they reported to be married or in partnership, to have children, to be less educated or to have higher body mass indices. Current weight categories differed significantly in the three age groups, with $66 \%$ of the youngest and $54 \%$ of the middleaged men reporting a BMI in the normal range of 18.5-24.9 as opposed to only $27 \%$ of the older men who were highly overweight and obese (73\%). Over three-quarters of all men reported daily or intensive sports activity (4-6 times a week), the youngest being significantly more active than the middle-aged and at a trend level than the oldest group. Excessive exercise exhibited significant differences between the groups (46\% in youngest versus $22 \%$ in middle-aged versus $11 \%$ in oldest men), indicating high levels of maladaptive sports behavior. Reasons for sports activity did not distinguish the groups significantly.

Table 1 Demographics, weight and sport characteristics

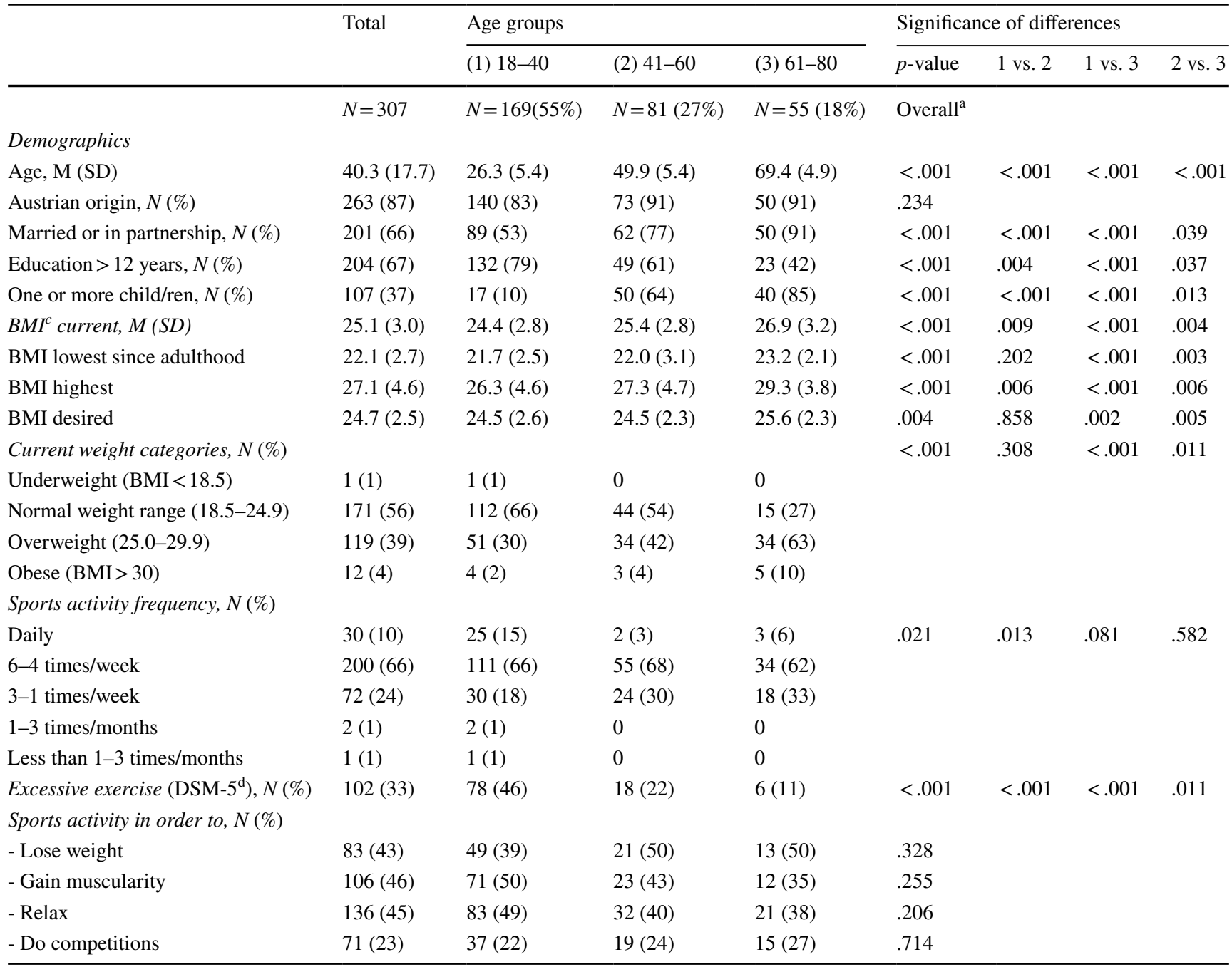

Due to missing observations, frequencies in the individual age groups do not always add up to the total number in this group

${ }^{a}$ Group comparisons by the Kruskal-Wallis test for ordinal and for continuous variables, and the Chi-square test for categorical variables

${ }^{\mathrm{b}}$ Adjusted for current BMI by analysis of covariance or ordinal logistic regression (for categorical variables)

${ }^{\mathrm{c}}$ Body mass index

${ }^{\mathrm{d}}$ Excessive exercise defined by (a) sports activity despite current physical pain or injury or (b) thinking of sports instead of concentrating on work or (c) conflicts with family or friend because of sports activity 


\section{Eating behavior and body image perception}

The Global score of the EDE-Q distinguished the three groups significantly, showing a lower score in the middle-aged men compared to both the youngest and the older men (Table 2). Most of the subscales of the EDE-Q revealed similar scores among the three groups, and only the "restraint" scale showed differences. Using the EDE-Q

Table 2 Eating behavior and body image

\begin{tabular}{|c|c|c|c|c|c|c|c|c|c|}
\hline & \multirow[t]{2}{*}{ Total } & \multicolumn{3}{|l|}{ Age groups } & \multicolumn{4}{|c|}{ Significance of differences } & \multirow[t]{2}{*}{$p$-value } \\
\hline & & $18-40$ & $41-60$ & $61-80$ & $p$-value & 1 vs. 2 & 1 vs. 3 & 2 vs. 3 & \\
\hline & $N=307$ & $N=169(55 \%)$ & $N=81(27 \%)$ & $N=55(18 \%)$ & Overall $^{\mathrm{a}}$ & & & & Adjusted $^{\mathrm{b}}$ \\
\hline EDE- $Q^{c}$, Global Score, $M(S D)$ & $0.8(0.7)$ & $0.9(0.7)$ & $0.7(0.7)$ & $0.9(0.8)$ & .039 & .022 & .635 & .033 & .065 \\
\hline - Restraint & $1.2(1.2)$ & $1.3(1.2)$ & $1.0(1.2)$ & $1.1(1.4)$ & .028 & .012 & .125 & .520 & .010 \\
\hline - Eating concern & $0.3(0.5)$ & $0.3(0.5)$ & $0.2(0.5)$ & $0.3(0.5)$ & .488 & & & & \\
\hline - Weight concern & $0.8(0.9)$ & $0.8(0.9)$ & $0.7(0.9)$ & $1.0(1.0)$ & .089 & & & & \\
\hline - Shape concern & $1.0(1.1)$ & $1.0(1.0)$ & $0.9(1.1)$ & $1.2(1.1)$ & .214 & & & & \\
\hline EDE-Q cutoff $>1.68, N(\%)$ & $34(11)$ & $18(11)$ & $7(9)$ & $8(15)$ & .562 & & & & \\
\hline EDE-Q cutoff $>2.3, N(\%)$ & $15(5)$ & $8(5)$ & $5(6)$ & $2(4)$ & .752 & & & & \\
\hline $\begin{array}{l}\text { Any eating disorder symptoms (EDS), } \\
N(\%)\end{array}$ & $31(10)$ & $24(14)$ & $6(7)$ & $1(2)$ & .019 & .148 & .012 & .241 & .035 \\
\hline EDS $S^{d}$ type, $N(\%)$ & & & & & .188 & & & & \\
\hline$-\mathrm{BMI}<18.5$ and fat phobia & 0 & 0 & 0 & 0 & & & & & \\
\hline - Binges eating & $23(8)$ & $17(10)$ & $5(6)$ & $1(2)$ & & & & & \\
\hline - Binges and purging* & $5(2)$ & $4(2)$ & $1(1)$ & 0 & & & & & \\
\hline Vomiting & 1 & 1 & 0 & 0 & & & & & \\
\hline Excessive exercise & 4 & 3 & 1 & 0 & & & & & \\
\hline - Purging behavior & $3(1)$ & $3(2)$ & 0 & 0 & & & & & \\
\hline Vomiting & 3 & 3 & 0 & 0 & & & & & \\
\hline - No symptom & $274(90)$ & $145(86)$ & $75(93)$ & $54(98)$ & & & & & \\
\hline Lifetime restricting diet behavior, $N(\%)$ & & & & & 672 & & & & \\
\hline Never & $185(61)$ & $102(61)$ & $51(64)$ & $32(59)$ & & & & & \\
\hline Up till 20 times & $104(34)$ & $61(36)$ & $24(30)$ & $19(35)$ & & & & & \\
\hline$>20$ times & $13(4)$ & $5(3)$ & $5(6)$ & $3(6)$ & & & & & \\
\hline $\begin{array}{l}\text { Lifetime history of an eating disorder, } \\
N(\%)\end{array}$ & $3(2)$ & $3(3)$ & 0 & 0 & .495 & & & & \\
\hline \multicolumn{10}{|l|}{ Body image } \\
\hline Satisfaction with weight? N(\%) & & & & & .001 & .003 & .003 & .220 & .167 \\
\hline Satisfied & $193(64)$ & $103(61)$ & $58(73)$ & $32(58)$ & & & & & \\
\hline Moderately satisfied & $73(24)$ & $53(31)$ & $10(13)$ & $10(18)$ & & & & & \\
\hline Dissatisfied & $38(13)$ & $13(8)$ & $12(15)$ & $13(24)$ & & & & & \\
\hline Satisfaction with shape? $N(\%)$ & & & & & .006 & .002 & .175 & .122 & .006 \\
\hline Satisfied & $185(61)$ & $94(56)$ & $59(75)$ & $32(58)$ & & & & & \\
\hline Moderately satisfied & $85(28)$ & $60(36)$ & $11(14)$ & $14(26)$ & & & & & \\
\hline Dissatisfied & $33(11)$ & $15(9)$ & $9(11)$ & $9(16)$ & & & & & \\
\hline "Do you like your body? N (\%) & & & & & .049 & .126 & .170 & .008 & .094 \\
\hline Yes & $244(81)$ & $136(81)$ & $70(89)$ & $38(69)$ & & & & & \\
\hline No & $48(16)$ & $25(15)$ & $9(11)$ & $14(26)$ & & & & & \\
\hline Do not know & $10(3)$ & $7(4)$ & 0 & $3(6)$ & & & & & \\
\hline
\end{tabular}

Due to missing observations, frequencies in the individual age groups do not always add up to the total number in this group

${ }^{a}$ Group comparisons by the Kruskal-Wallis test for ordinal and for continuous variables, and the Chi-square test for categorical variables

${ }^{b}$ Adjusted for current BMI by analysis of covariance or ordinal logistic regression (for categorical variables)

${ }^{c} \mathrm{EDE}-\mathrm{Q}=$ Eating Disorder Examination Questionnaire

${ }^{\mathrm{d}} \mathrm{EDS}=$ Eating disorder symptoms 
cutoff-scores as indicators for disordered eating, both the general (prevalence rate: 4-6\%) and the male-specific cutoff (rate: 9-15\%) did not distinguish the three groups. From the perspective of eating disorder symptomatology, $31(10 \%)$ of all male respondents met criteria for current eating disorder symptoms (EDS) most with regard to binge eating, followed by binge eating and purging and purging without binge eating (see Table 2). The three age groups differed significantly from each other by a striking decrease, showing the highest prevalence rates of EDS in the youngest group (14\%) and lowest in the oldest group (2\%) (adjustment for current BMI did not alter this finding). Of note, purging in the context of bulimic behavior was predominately based on excessive exercising and not on self-induced vomiting as typically associated with pathological eating behavior in women. Lifetime restricting dieting indicated no differences between the groups and prevalence rates were low in males of all groups. The question with regard to lifetime eating disorder resulted in three positive answers in the whole sample (2\%).

With regard to body image, the majority of all men were satisfied with their weight and shape and agreed to the sentence: "I like my body". However, comparison by age group revealed significant differences between all three groups showing the middle-aged men as the most satisfied with weight and shape and most body liking group compared to the youngest and the oldest, respectively. However, after adjusting for current BMI, only satisfaction with shape remained significant.

\section{Discussion}

We used an anonymous questionnaire to assess eating behavior including prevalence rates of eating disorder symptoms, frequency and intensity of sports activity, and body image in 307 fitness center-attending men, aged 18-80 years, recruited from two of the largest fitness centers in Innsbruck, Austria. To the best of our knowledge, this is the first study of fitness center men on eating behavior and associated features. Our study yielded four main findings.

First, we found disturbed eating behavior in all age groups assessed by the EDE-Q global score and based on both EDE-Q cutoff scores (general and men specific as described above). Our findings in fitness center men differ from a prior community study [33] that included women and men, aged 24 up till 75 years based on the comparison with the data presented in the graph of Hilbert et al.'s study [33]. Our sample seems to show much higher scores (almost double) of the EDE-Q (with the exception of the "eating concern"), indicating pathological eating behavior as compared to the male subjects of the Hilbert study (values were drawn from the graph and compared to ours). In line, the fitness center men of our study displayed more than three times higher rates of the EDE-Q cutoff score $\geq 2.3$ as compared to the community men (5\% vs $1.5 \%$ ). In future studies, a statisticalbased comparison should be performed.

Secondly, with regard to eating disorder symptomatology, $10 \%$ of all men met criteria with the highest rates observed in the youngest group, followed by the middle-aged and the oldest men. Binge eating was the most frequent symptom, followed by binging and purging. Men with bulimic symptoms predominately reported using excessive exercise to compensate for binging. This finding goes along with results from an earlier study of our group on eating disorder symptoms in community men aged $40-75$ years [18]. In this sample $(N=470)$, we found $7 \%$ meeting criteria for eating disorder symptoms as described above and four out of seven who used excessive exercising (maladaptive pattern) as the purging method. Similar to "muscularity-oriented eating disorders" as described recently [11, 12], excessive exercising appears as a male-specific characteristic in the context of eating disorders. Excessive exercising, previously described as an expression of male coping strategies for comorbid depression [34], may serve in the context of disordered eating as a strategy for acute emotion regulation [35, 36].

Thirdly, our data show a large discrepancy between eating disturbances as identified by EDE-Q and DSM-5 symptoms and the self-reported eating disorders suggesting a lack of awareness of the pathological pattern of eating behavior in men. Only 3 men reported a lifetime eating disorder, while we found 31 men with EDS and 15-34 men with disordered eating as defined by EDE-Q cutoff scores. This could be due to the fact that eating disorders are still predominately associated with female gender, and therefore pathological eating behavior especially when related to sports activity is just not associated with "eating disorders" by concerned men [37].

Fourthly, variables on body image showed high proportions of men who are satisfied with their weight, shape, and their body as a whole. This differs strongly from studies on women across ages [e.g. 38].The intensity of their training (almost $80 \%$ of all men exercised 4-7 times per week) could be one reason for the high proportion of positive body image, as well as the consequence of the high score of restraint eating (=high discipline in eating behavior including healthy and low caloric nutrition).

\section{Strengths and limits}

This study adds to the very limited data on eating behavior in men of different ages in the context of fitness sport.

Several limitations of the study should be recognized. First, our participation rate of this study was $46 \%$ raising the possibility of non-response bias and selection bias, respectively. However, our response rate is equivalent to the finding of a meta-analysis of Shih and Fan [39] who showed response rates of mail surveys to be $10 \%$ higher than the 
rates of web surveys (45\% vs. 34\%). Further, since eating disorders are often secret, participants with disordered eating may have been less likely to respond than those without, causing an underestimation of the true rate. On the other side, the true prevalence of eating behaviors could be overestimated such as binge eating if individuals with this behavior were more likely to respond or if they overstated the severity. Also, the combination of disordered eating and excessive exercise might be associated with hyperactivity and/or impulsivity, characteristics that could cause rejection of study participation. Second, the classification into weight categories based on current BMI could be biased due to the lack of assessment of body fat or muscularity. However, most people do not know their exact proportion of body fat, and therefore we did not include this question in our questionnaire. This should be considered in future studies. Thirdly, we used the EDE-Q next to other variables. It is important to state that the EDE-Q as a questionnaire is not able to assess the complexity and multidimensionality of "eating behavior" and "body image. Fourthly, we used a selection of items of the EDS-21 and the EAI to prove the criteria of "excessive sports" described in DSM-5. This has to be considered carefully in future studies. Finally, we used self-report eating disorder questions and key symptoms of eating disorder diagnosis, rather than performing clinical interviews. Therefore, it is important to state that our findings are indicative of disordered eating. However, our questions were based on standardized instruments (e.g., the EDE-Q and the DSM-5 clinical criteria for eating disorders) which are commonly used in research on eating behavior [28] and in our prior studies in men [40].

In summary, the present results provide clear evidence that disordered eating based on EDE-Q and DSM-5 eating disorder symptoms do occur in men across all ages attending fitness centers. In addition, our findings indicate that excessive exercise is a male-specific purging method after binging. Furthermore, it appears that in the context of sports activity eating disorder symptoms are mostly under-recognized by affected men, possibly due to the fact that eating disorders are still seen as primarily female disorders. More male-specific research is needed to increase attention and knowledge about disordered eating in men of fitness centers and its special characteristics.

\section{What is already known on this subject?}

Studies on men are still less than $1 \%$ of all eating disorder research. There are special characteristics of disordered eating in men such as the focus on muscularity and sports [11, 37]. Including these aspects, the prevalence numbers has risen up to $20-30 \%$ of risky eating behaviors [37].

\section{What does this study add?}

We compared younger, middle-aged and older men and found disordered eating as defined by the EDE-Q and DSM-5 key symptoms (i.e., BMI $<18.5$ and fat phobia, binge eating, purging behaviors, excessive exercise) in all groups. Our results showed that $10 \%$ of fitness-center attendees had symptoms of disordered eating and that the sport context may be involved with this [38].

Author contributions BM-M contributed to conception and design, development of methodology, analysis and interpretation of data, drafting and revision of the manuscript, and study supervision. BM-M has full access to all data of the study and takes responsibility for the integrity of the data and the accuracy of the analysis. BD contributed to conception and design, development of methodology, acquisition, analysis and interpretation of data, and drafting and revision of the manuscript. IE contributed to the conception and design, development of methodology, acquisition, analysis and interpretation of data, and drafting and revision of the manuscript. VW contributed to conception and design, development of methodology, analysis and interpretation of data, drafting and revision of the manuscript. GK contributed to conception and design, development of methodology, analysis and interpretation of data, and revision of the manuscript. CSB contributed to the conception and design, development of methodology, and revision of the manuscript. CIR contributed to the conception and design, development of methodology, drafting and revision of the manuscript, and study supervision.

Funding Open access funding provided by University of Innsbruck and Medical University of Innsbruck. This study was not supported by any funding.

Data availability The data that support the findings of this study are available from the corresponding author upon reasonable request.

\section{Declarations}

Conflict of interest All of the authors declare that no conflict of interest exists.

Ethical approval All procedures were approved by the Ethics Commission of the Medical University Innsbruck and were conducted in accordance with the 1964 Helsinki Declaration and its later amendments or comparable ethical standards.

Informed consent Informed consent was obtained from all individual participants included in the study.

Open Access This article is licensed under a Creative Commons Attribution 4.0 International License, which permits use, sharing, adaptation, distribution and reproduction in any medium or format, as long as you give appropriate credit to the original author(s) and the source, provide a link to the Creative Commons licence, and indicate if changes were made. The images or other third party material in this article are included in the article's Creative Commons licence, unless indicated otherwise in a credit line to the material. If material is not included in the article's Creative Commons licence and your intended use is not permitted by statutory regulation or exceeds the permitted use, you will 
need to obtain permission directly from the copyright holder. To view a copy of this licence, visit http://creativecommons.org/licenses/by/4.0/.

\section{References}

1. Stapleton P, McIntyre T (2016) A body image avoidance, body dissatisfaction, and eating pathology: is there a difference between male gym users and non-gym users? Am J Mens Health 10(2):100-109. https://doi.org/10.1177/1557988314556673

2. Lichtenstein MB, Hinze CJ, Emborg B, Thomsen F, Hemmingsen SD (2017) Compulsive exercise:links, risks and challenges faced. Psychol Res Behav Manag 10:85-95. https://doi.org/10. 2147/PRBM.S113093

3. Hausenblas HA, Schreiber K, Smoliga JM (2017) Addiction to exercise. BMJ. https://doi.org/10.1136/bmj.j1745

4. Di Lodovico L, Poulnais S, Gorwood P (2019) Which sports are more at risk of physical exercise addiction: a systematic review. Addict Behav 93:257-262. https://doi.org/10.1016/j. addbeh.2018.12.030

5. American Psychiatric Association (2013) Diagnostic and statistical manual of mental disorders 5th ed. Washington, DC American Psychiatric Association; German Version: Falkai \& Wittchen (eds) Diagnostisches und Statistisches Manual Psychischer Störungen DSM 5, Hogrefe (2015)

6. Cook B, Hausenblas H, Crosby RD, Cao L, Wonderlich SA (2015) Exercise dependence as a mediator of the exercise and eating disorder relationship: A pilot study. Eat Behav 16:9-12. https://doi.org/10.1016/j.eatbeh.2014.10.012

7. Sundgot-Borgen J, Torstveit MK (2004) Prevalence of eating disorders in elite athletes is higher than in the general population. Clin J Sport Med 14:24-32. https://doi.org/10.1097/00042 752-200401000-00005

8. Nattiv AR, Agostini B, Drinkwater B, Yeager KK (1994) The female athlete triad. The inter-relatedness of disordered eating, amenorrhea, and osteoporosis. Clin Sports Med 13:405-418

9. Strother E, Lemberg R, Stanford SCH, Turberville D (2012) Eating disordered men: Underdiagnosed, undertreated, and misunderstood. Eat Disord 20:346-355. https://doi.org/10.1080/ 10640266.2012.715512

10. Pope HG, Phillips KA, Olivardia R (2000) The Adonis Complex. The Secret Crisis of Male Obsession. The Free Press, Simon \& Schuster Inc, New York

11. Lavender JM, Brown TA, Murray SB (2017) Men, muscles, and eating disorders: An overview of traditional and muscularityoriented disordered eating. Curr Psychiat Res 19:32. https://doi. org/10.1007/s11920-017-0787-5

12. Murray SB, Griffiths S, Mitchison D, Mond JM (2016) The transition from thinness-oriented to muscularity-oriented disordered eating in adolescent males A clinical observation. J Adolesc Health. https://doi.org/10.1016/j.jadohealth.2016.10.014

13. Müller A, Loeber S, Söchtig J, Te Wildt B, De Zwaan M (2015) Risk for exercise dependence, eating disorder and addictive behaviors among clients of fitness centers. J Behav Addict 4(4):273-280. https://doi.org/10.1556/2006.4.2015.044

14. Lichtenstein MB, Emborg B, Hemmingsen SD, Hansen NB (2017) Is exercise addiction in fitness centers a socially accepted behavior? Add Behav Rep 6:102-105. https://doi.org/10.1016/j. abrep.2017.09.002

15. Colledge F, Cody R, Gerber M (2020) Responses of fitness center employee to cases of suspected eating disorders or excessive exercise. J Eat Disord 8:8. https://doi.org/10.1186/ s40337-020-0284-9
16. Manley RS, O’Brien KM, Samuels S (2008) Fitness instructors' recognition of eating disorders and attendant ethical/liability issues. Eat Disord 16(2):103-116. https://doi.org/10.1080/10640 260801887162

17. Höglund K, Normen L (2002) A high exercise load is linked to pathological weight control behavior and eating disorders in female fitness instructors. Scand J Med Sci Sports 12:261-275. https://doi.org/10.1034/j.1600-0838.2002.10323.x

18. Mangweth-Matzek B, Kummer K, Pope HG (2016) Eating disorder symptoms in middle-aged and older men. Int J Eat Disord 49(10):953-957. https://doi.org/10.1002/eat.22550

19. Mond J, Gorell S (2021) "Excessive exercise" in eating disorders research: problems of definition and perspective. Eat Weight Disord 26:1017-1020. https://doi.org/10.1007/s40519-020-01075-3

20. Hausenblas HA, Symons Downs D (2002) Exercise dependence: A systematic review. Psychol Sport \& Exerc 3:89-123. https://doi. org/10.1016/S1469-0292(00)00015-7

21. Müller A, Claes L, Smits D et al (2013) Validation of the German version of the exercise dependence scale. Europ J Psychol Assess 29(3):213-219. https://doi.org/10.1027/1015-5759/ a000144

22. Terry A, Szabo A, Griffiths M (2004) The exercise addiction inventory: a new brief screening tool. Addict Res Theory 12:489-499. https://doi.org/10.1080/16066350310001637363

23. Ziemainz H, Stoll O, Drescher A et al (2013) Die Gefährdung zur Sportsucht in Ausdauersportarten. Dtsch Z Sportmed 64:57-64. https://doi.org/10.5960/dzm.2012.057

24. Fairburn CG, Beglin SJ (1994) The assessment of eating disorders: Interview or self-report questionnaire? Int J Eat Disord $16: 363-370$

25. Hilbert A, Tuschen-Caffier B (2006) Eating Disorder Examination-Questionnaire. Deutschsprachige Übersetzung. PAG Institut für Psychologie AG, Münster: Verlag für Psychotherapie 1. Auflage

26. Schaefer LM, Smith KE, Leonard R, Wetterneck Ch, Smith B, Farrell N, Riemann, et al (2018) Identifying a male clinical cutoff on the eating disorder examination-questionnaire EDE-Q. Int J Eat Disord 51(12):1357-1360. https://doi.org/10.1002/eat. 22972

27. Mond JM, Hay PJ, Rodgers B et al (2006) Eating disorder examination questionnaire (EDE-Q): norms for young adult women. Behav Res Ther 44:53-62. https://doi.org/10.1016/j.brat.2004.12. 003

28. Gagne DA, Von Holle A, Brownley KA, Runfola CD, Hofmeier S, Branch KE et al (2012) Eating disorder symptoms and weight shape concerns in a large web-based convenience sample of women aged 50 and above: Results of the gender and body image [GABI] study. Int J Eat Disord 45:832-844. https://doi.org/10. 1002/eat.22030

29. SPSS (2008) Statistical package for social science 20.0 for windows. Chicago (IL): SPSS Inc

30. Levin JR, Serlin RC, Seaman MA (1994) A controlled powerful multiple-comparison strategy for several situations. Psychol Bull 115:153-159

31. Cohen J (1992) A power primer. Psychol Bull 112(1):155-159. https://doi.org/10.1037/0033-2909.112.1.155

32. Chen H, Cohen P, Chen S (2010) How big is a big odds ratio? Interpreting the magnitudes of odds ratios in epidemiological studies. Commun Statist Simul Commun 39:860-864. https:// doi.org/10.1080/03610911003650383

33. Hilbert A, de Zwaan M, Braehler E (2012) How frequent are testing disturbances in the population. Norms of the eating disorder examination questionnaire. PLoS ONE 7(1):e29125. https://doi. org/10.1371/journal.pone.0029125

34. Valls M, Callahan S, Rousseau A, Chabrol H (2014) Troubles du comportement alimentaire et symptomatologie dépressive: étude 
épidémiologique chez les jeunes hommes. Encephale 40:223-230. https://doi.org/10.1016/j.encep.2013.05.003

35. Bartholomew JB, Morrison D, Ciccolo JT (2005) Effects of acute exercise on mood and well-being in patients with major depressive disorder. Med Sci Sports Exerc 37:2032-2037. https://doi.org/10. 1249/01.mss.0000178101.78322.dd

36. Colledge F, Sattler I, Schilling H, Gerber M, Pühse U, Walter M (2020) Mental disorders in individuals at risk for exercise addiction - A systematic review. Addict Behav Rep 12:100314. https:// doi.org/10.1016/j.abrep.2020.100314

37. Nagata JM, Brown TA, Murray SB, Lavender JM (2021) Eating disorders in boys and men. Switzerland, Springer Nature Switzerland AG. https://doi.org/10.1007/978-3-030-67127-3

38. Mangweth-Matzek B, Rupp CI, Hausmann A, Assmayr K, Mariacher E, Kemmler G et al (2006) Never too old for eating disorders or body dissatisfaction: a community study of elderly women. Int J Eat Disord 39(7):583-586. https://doi.org/10.1002/eat.20327

39. Shih TH, Fan X (2008) Comparing response rates from web and mail surveys: a meta-analysis. Field Methods 20(3):249-271. https://doi.org/10.1177/1525822X08317085

40. Kummer K, Pope HG, Hudson JI, Kemmler G, Pinggera GM, Mangweth-Matzek B (2019) Aging male symptomatology and eating behavior. Aging Male 22:55-61. https://doi.org/10.1080/ 13685538.2018 .1477931

Publisher's Note Springer Nature remains neutral with regard to jurisdictional claims in published maps and institutional affiliations. 